\title{
FLOODPLAIN MAPPING AND VISUALIZATION FOR FLOOD RISK ASSESSMENT AND DECISION SUPPORT IN SARAWAK KANAN RIVER
}

FREDERIK JOSEP PUTUHENA

DARRIEN YAU SENG MAH

Universiti Malaysia Sarawak

SAI HIN LAI

Universiti Sains Malaysia

\begin{abstract}
Sarawak Kanan River is one of the tidal rivers frequently affected by flood in Sarawak, Malaysia. Over the years, physical development has been concentrated in the middle valley town of Bau, where the center of administration and commerce for the district is located. The town of Bau and surrounding areas is a well known flood-prone area, for being geographically located in the floodplain of Sarawak Kanan River. Major floods of February 2003 and January 2004 had Bau and surrounding areas flood-stricken. The area has little hydrological information to ponder with, thus indicating a need of a flood visualization model to have a better explanation of the flooding scenarios in the floodplain areas. For this purpose, the flooding of Sarawak Kanan River was modeled using the InfoWorks RS one-dimensional hydrodynamic model. The inputs consist of observed discharge hydrographs of upstream Buan Bidi sub-catchment and lumped synthetic discharge hydrographs of ungauged sub-basins. Observed stage hydrographs measured at Siniawan were used as downstream input. This article outlined the methodology for flood mapping and visualization to enable flood risk assessment and decision support modeling for future development in floodplain protection and control. The model was capable of providing an acceptable estimate of flood depths with a correlation coefficient of 0.83 .
\end{abstract}

(c) 2010, Baywood Publishing Co., Inc.

doi: 10.2190/ES.32.3.b

http://baywood.com 